\title{
The bending properties of bamboo strand board l-beams
}

\author{
Yuhui Sun ${ }^{1,2,3}$, Zehui Jiang ${ }^{1,2}$, Huanrong Liu ${ }^{1,2}$, Zhengjun Sun ${ }^{1,2}$ and Changhua Fang ${ }^{1,2^{*}}$ (D)
}

\begin{abstract}
Novel bamboo I-beams fabricated from bamboo oriented strand boards as structural members were investigated. Bending tests were performed to determine the stiffness and strength properties of bamboo I-beams. The results showed that the stiffness and strength properties exceeded the requirements of APA EWS Performance-Rated I-joist in PRI-400-2012. Increasing section depth had obvious effect on the ultimate load capacity, stiffness and failure mode of bamboo I-beams. Moreover, the bending properties of bamboo I-beams were also affected by flange materials, joint type in web, and reinforcement of flange finger joints. The strain measurements indicated that the plane assumption could be applied to the bamboo I-beams. Based on the stiffness calculation formula of I-beams recommended in Canadian standard and the moment capacity calculation formula corresponding to each failure mode of I-beams, the calculated stiffness and ultimate load capacity of specimens were relatively close to the experimental results.
\end{abstract}

Keywords: Bamboo I-beam, Bamboo orientated strand board, Bending properties, Flange materials, Type of web joint

\section{Introduction}

In recent years, wood constructions have increased considerably and wood I-beams are widely used in residential or public buildings. Wood I-beam is the main load-bearing member in wood constructions and its performance directly determines the safety of the whole structure. Wood I-beam is able to bear the same load as solid core wooden beam at the cost of considerably less materials. In addition, it has low performance variability and good dimensional stability $[1,2]$. Constituent materials, joints, and geometry influence short- and long-term performances of I-beams [3-8].

Bamboo is abundantly available in many countries and it is a very promising substitution for wood due to its rapid growth and high tensile strength. The design and use of structural bamboo products allows great demands of this renewable resource. The bamboo oriented strand board process represents one of the best opportunities

\footnotetext{
*Correspondence: cfang@icbr.ac.cn

${ }^{1}$ International Centre for Bamboo and Rattan (ICBR), Beijing 100102,

China

Full list of author information is available at the end of the article
}

for automation, property control and consistency, mass production, and resin efficiency in manufacture of bamboo-based building materials, with minimal waste. It is an excellent industrial material as a substitute for wood structural board $[9,10]$. The applications of bamboo strand board in building structures, such as bamboo I-beam, can broaden the utilization scope of bamboo. The design and manufacturing technology of I-beams made of bamboo-based composites were reported [11]. For instance, the fabrication of I-beams with glue-laminated bamboo in flanges and plywood or oriented strand board in webs [12,13], and bamboo I-beam made of bamboo plywood flange and web [14] were investigated. Therefore, it was believed that both bending and shearing properties of bamboo I-beam were qualified for structural proposes. However, bamboo I-beams made of bamboo orientated strand board (bamboo I-beam for short in the following text) was seldom reported despite the high structural strength of bamboo orientated strand boards.

The critical properties of I-beams for residential construction are bending strength and stiffness [15]. In this paper, the influences of various factors including web type, flange material and beam depth on bending 
performance of I-beams were explored, and the ultimate load capacity and stiffness of I-beam were also predicted. The study provided a theoretical basis for the design and application of bamboo I-beams in construction.

\section{Materials and methods Materials}

Four- to six-year-old bamboo (Dendrocalamus giganteus Munro) collected from Mangshi, Yunnan, China, was used for this study. Bamboo strands were 150-mm long (longitudinal), $0.8-\mathrm{mm}$ thick (radial), and 5- to $60-\mathrm{mm}$ wide (tangential), and the moisture content was $5 \%$. Emulsion polymer isocyanate (Yunnan Yonglifa Industry Co., Ltd, China) was used as adhesive for bonding strands. The mass fraction of adhesive was $6 \%$ based on oven-dry strand mass. Bamboo orientated strand boards were prepared at beltline scale with a hydraulic hot press to obtain final dimension of $2440 \mathrm{~mm} \times 1220 \mathrm{~mm} \times t$ $\mathrm{mm}$, where $t$ is the thickness, and the target density was $0.9 \mathrm{~g} \mathrm{~cm}^{-3}$. The boards were hot-pressed under a pressure of $3-4 \mathrm{MPa}$ at $160-165{ }^{\circ} \mathrm{C}$. The duration of pressing varied depending on board thickness $\left(1.25 \mathrm{~min} \mathrm{~mm}^{-1}\right)$. The produced boards differed in the strand orientation distribution. Two distinctive orientation types were prepared: (1) bamboo fibers primarily oriented along the length of the member (LBSL) $(t=28 \mathrm{~mm})$; and (2) a typical threelayer assembly with aligned strands on the two surface layers and orthogonally oriented strands in the core layer (BOSB) $(t=15 \mathrm{~mm})$. The weight ratio set of face-to-coreto-back layers of BOSB was 1:2:1. The LBSL and BOSB were used as flanges and webs, respectively. After that, the boards were conditioned in a chamber at $25-30{ }^{\circ} \mathrm{C}$ with $60-65 \%$ relative humidity. LBSL and BOSB boards were produced in Yunnan Yonglifa Industry Co., Ltd. According to ASTM D1037-12 [16], bending, tensile and edgewise shear test procedures were adapted to determine mechanical performance of the two boards. The test results are summarized in Table 1 and each experiment had six replications.

Douglas fir (Pseudotsuga menziesii) timber was purchased from Shanghai Zhuangyi Wood Industry Co., Ltd.
The flange timber met the requirements of No. 2 grade of Japanese Agricultural Standard (JAS). The final crosssectional size was $28 \mathrm{~mm} \times 66 \mathrm{~mm}$ after finger-jointing. Its air-density and moisture content were $0.52 \mathrm{~g} \mathrm{~cm}^{-3}$ and $8 \%$, respectively. The parameters measured for Douglas fir were air-dry density, modulus of rupture, bending modulus of elasticity, tensile strength and shear parallel to grain (tangential) in accordance with ASTM D143-14 [17]. Physical and mechanical properties are shown in Table 1.

The adhesive used for bonding web to flange was a commercially available resorcinol-phenol-formaldehyde adhesive (Beijing Dynea Chemical Industry Co. Ltd, China) and its main agent to curing agent ratio was 100:15. The solid content, viscosity at $23^{\circ} \mathrm{C}$, and $\mathrm{pH}$ value were $65 \%, 15 \mathrm{~Pa}$ s, and 7.5, respectively.

\section{Preparation of I-beams}

Firstly, boards were planed into a uniform thickness and cut into required size of I-beams. Horizontal finger joint of LBSL flanges and some BOSB webs with resorcinolphenol-formaldehyde adhesive $\left(290 \mathrm{~g} \mathrm{~m}^{-2}\right)$ are shown in Fig. 1. Stagger-jointed assembling was designed as shown in Fig. 2 for flanges and webs. The webs were glued at upper and lower edges to LBSL or timber flanges to form I-shape cross-section, as shown in Fig. 2. Flange and web were laminated with resorcinol-phenol-formaldehyde adhesive $\left(290 \mathrm{~g} \mathrm{~m}^{-2}\right)$ under pressure of $2 \mathrm{MPa}$ for $4 \mathrm{~h}$.

Different types of I-beams were made in this study to investigate the influences of different factors, including I-beam depths $(300-600 \mathrm{~mm})$, type of flanges (timber or LBSL) and joint types in web, as shown in Table 2, on I-beam mechanical properties. The joint types in web included finger-joint (Fig. 1b) and joint with nail-glued timber (nail diameter: $2 \mathrm{~mm}$; nail length: $56 \mathrm{~mm}$ ) (Fig. 2c). The details of the nail-glued timber are shown in Fig. 2c. Moreover, in all bamboo I-beams except for B300-1, flange finger joints were reinforced with nail-glued timbers (Douglas fir, 300-mm long, 66- or 100-mm wide depending on the height of flange $\left(h_{j}\right), 18$-mm thick). All test samples were stored at $20 \pm 2{ }^{\circ} \mathrm{C}$ and $65 \pm 3 \%$ relative humidity until their

Table 1 Mechanical properties of individual materials

\begin{tabular}{|c|c|c|c|}
\hline Physical and mechanical properties & BOSB & LBSL & Douglas fir timber \\
\hline Air-dry density $\left(\mathrm{g} \mathrm{cm}^{-3}\right)$ & $0.92(3.95 \%)$ & $0.9(5.45 \%)$ & $0.52(6.66 \%)$ \\
\hline Modulus of rupture (MPa) & $82.56(12.49 \%)$ & $66.91(10.61 \%)$ & $55.35(13.10 \%)$ \\
\hline Bending modulus of elasticity (GPa) & $10.25(6.46 \%)$ & $9.33(5.07 \%)$ & $11.50(5.99 \%)$ \\
\hline Tensile strength (MPa) & $28.71(9.87 \%)$ & $34.72(8.99 \%)$ & $83.50(10.23 \%)$ \\
\hline Shear strength (MPa) & $\begin{array}{l}16.54(10.66 \%) \text { (shear through } \\
\text { thickness) }\end{array}$ & $\begin{array}{l}12.87(11.24 \%) \text { (shear through } \\
\text { thickness) }\end{array}$ & $\begin{array}{l}9.00(12.03 \%) \text { (shear } \\
\text { parallel to grain) }\end{array}$ \\
\hline
\end{tabular}

Values in parentheses are coefficient of variation 


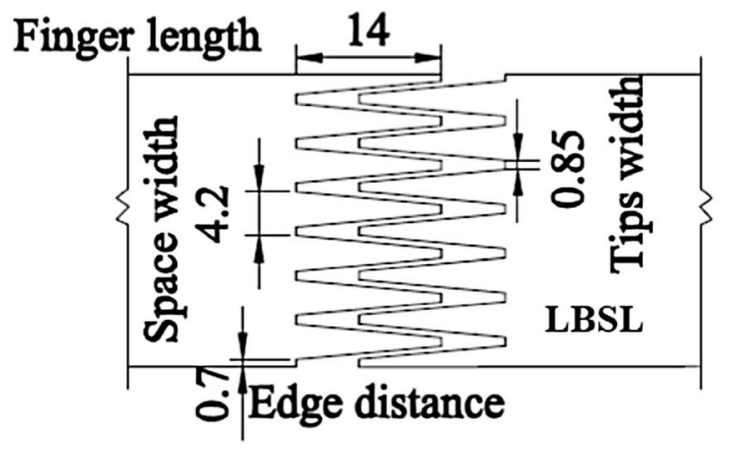

a

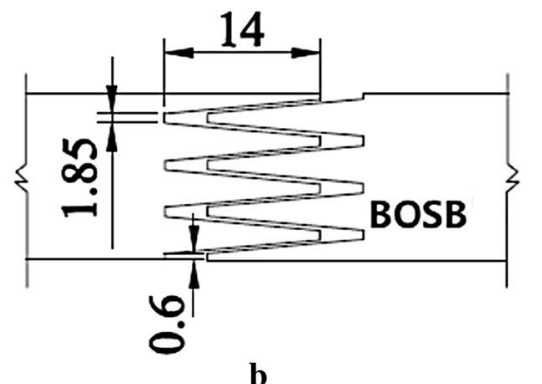

b

Fig. 1 Flange finger-joint (a) and web finger-joint (b) (mm)

moisture content reached approximately $12 \%$. Each group had three repetitions.

\section{I-beam testing and calculation}

According to ASTM D 5055-16 [18], four-point bending tests were performed with a loading rate of $5 \mathrm{~mm} \mathrm{~min}^{-1}$ (Fig. 3). The span $(L)$ of bending test was $6000 \mathrm{~mm}$ and the distance between two loading points was $1800 \mathrm{~mm}$. Moreover, the span of B300, B400 and B600 were 20, 15 and 10 times of the I-beams' depth, respectively. Three displacement sensors with a range of $120 \mathrm{~mm}$ (Shanghai Sanhai flowmeter Co., Ltd., China) were installed on specimens at the locations of mid-span and supports. Seven strain gauges (model: BX120-80AA, Xingdongfang engineering sensor Co., Ltd., China) were attached on the upper and lower flange edges (marked as "1" and "7") and the web (marked as "2" to "6") at mid-span from top to bottom to measure the strain distribution. The data were collected synchronously by DH3817 static strain testing system with a sampling frequency of $2 \mathrm{~Hz}$ (Donghua Testing Technology Co., Ltd, China). Eight lateral restraints were provided to prevent lateral buckling of I-beam. Additional stiffeners made of Douglas fir with a width of $120 \mathrm{~mm}$ and thickness of $38 \mathrm{~mm}$ were provided at locations of support and loading (Fig. 3) to prevent local bulking. Stiffeners were completely fastened to webs. One end of stiffeners was adhered to the inner surfaces of top or bottom flanges and the gap between the other end of stiffeners and flange without loading was $18 \mathrm{~mm}$.

The moment capacity $M_{\mathrm{u}}$ and the effective stiffness $(\mathrm{EI})_{0}$ were estimated according to Chinese National Standard GB/T 28985-2012:

$$
\begin{aligned}
& M_{\mathrm{u}}=\frac{P_{\max } a}{2}, \\
& (\mathrm{EI})_{0}=\frac{\Delta P a\left(3 L^{2}-4 a^{2}\right)}{48 \Delta y},
\end{aligned}
$$

where $P_{\max }$ is maximum damage load $(\mathrm{N}), L$ is the span between two support points $(\mathrm{mm}), a$ is the distance between loading and support $(\mathrm{mm}), \Delta P / \Delta y$ is the slope of the load-displacement curve $\left(\mathrm{N} \mathrm{mm}^{-1}\right)$. In addition, considering the serviceability criterion, the corresponding load at the deformation equal to $L / 250\left(P_{L / 250}\right)$ was estimated [19].

When the specimens were destroyed, the bending stress in tensile flange $(\sigma)$ and shear stress in the web $(\tau)$ of the I-beams could be calculated by formulas (3) and (4) according to pure bending theory in mechanics of materials:

$$
\begin{gathered}
\sigma=\frac{M_{\mathrm{u}}}{I_{\mathrm{ef}}} \frac{H}{2}, \\
\tau=\frac{V_{\mathrm{u}} S_{\mathrm{f}}}{I_{\mathrm{ef}} t},
\end{gathered}
$$

where $V_{\mathrm{u}}$ is the shear force at failure $(\mathrm{N}), I_{\mathrm{ef}}$ is cross-sectional moment of inertia of the neutral surface $\left(\mathrm{mm}^{4}\right), S_{\mathrm{f}}$ is the first moment of area of a flange $\left(\mathrm{mm}^{3}\right), H$ and $t$ are, respectively, the I-beam height and the web thickness.

\section{Results and discussion}

\section{Failure modes}

The failures of I-beams in this study occurred suddenly without any portents. For bamboo I-beam with a depth of $300 \mathrm{~mm}$ (B300-2), failure modes were dominated by flange failure in tension (FT) and flange failure in tension at finger joint (FTJ). FTJ was typically characterized by separation at one finger joint, and then delamination and separation at the other finger joint (Fig. 4a). Mark et al. [20] reported a similar phenomenon of failure. For bamboo I-beam with a depth of $400 \mathrm{~mm}$ (B400), the main failure modes were shear failure (SF), which occurred at the location of web-to-web joints following by debonding between web and flange (Fig. 4c). The discontinuity of 


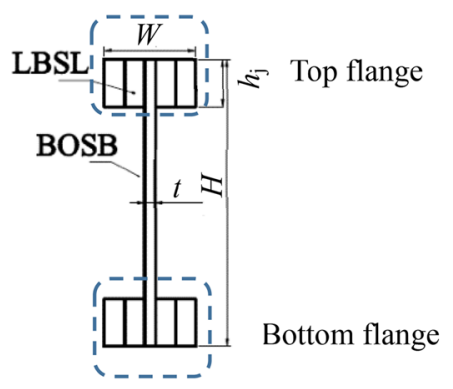

a

Finger joint on flange
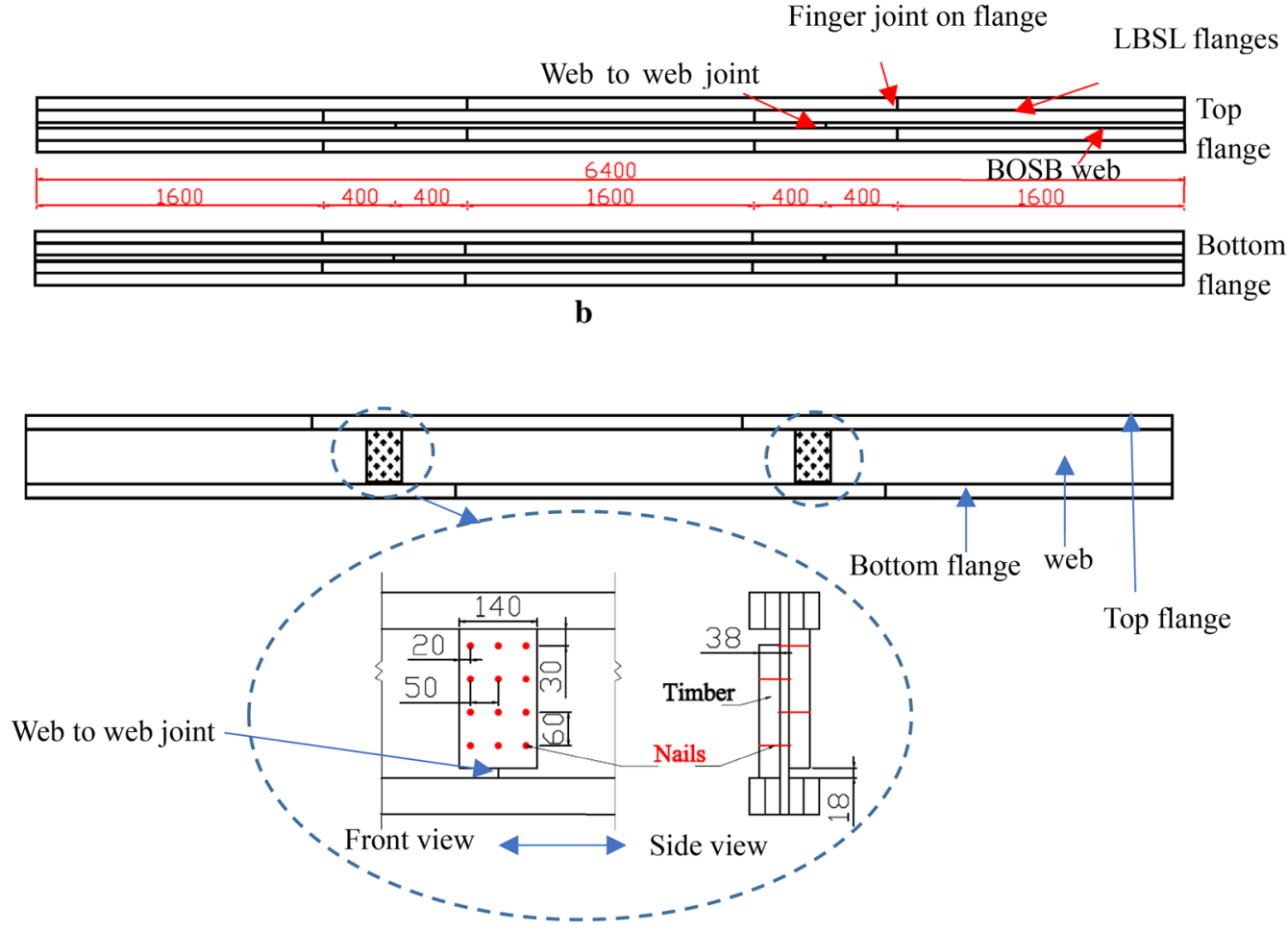

c

Fig. 2 Details of I-beam: a I-beam cross-section; $\mathbf{b}$ stagger-jointed assembling of flanges and web from top view of I-beam; c nail-glued timber on web-to-web joint (mm)

Table 2 Experimental design and dimensions of the beams

\begin{tabular}{llllllll}
\hline Beam type & Types of web joint & $\begin{array}{l}\text { Reinforcement } \\
\text { of finger-joint flange }\end{array}$ & $\begin{array}{l}\text { Beam length } \\
(\mathbf{m m})\end{array}$ & $\boldsymbol{W}(\mathbf{m m})$ & $\boldsymbol{H}(\mathbf{m m})$ & $\boldsymbol{h}_{j}(\mathbf{m m})$ & $\boldsymbol{t}(\mathbf{m m})$ \\
\hline B300-1 & Web finger-joint & Without & 6400 & 127 & 300 & 66 \\
B300-2 & Web finger-joint & With & 6400 & 127 & 300 & 66 \\
B300-3 & Nail-glued timber joint & With & 6400 & 127 & 300 & 66 & 15 \\
W300 & Nail-glued timber joint & Without & 6400 & 127 & 300 & 66 \\
B400 & Nail-glued timber joint & With & 6400 & 127 & 400 & 66 \\
B600 & Nail-glued timber joint & With & 6400 & 127 & 600 & 15 \\
\hline
\end{tabular}

B400 presents I-beam consisting of LBSL flange and BOSB web with a total depth of $400 \mathrm{~mm}$; W300 presents I-beam with BOSB web and timber flange. For $W, H, h_{j}$ and $t$, see Fig. 2 

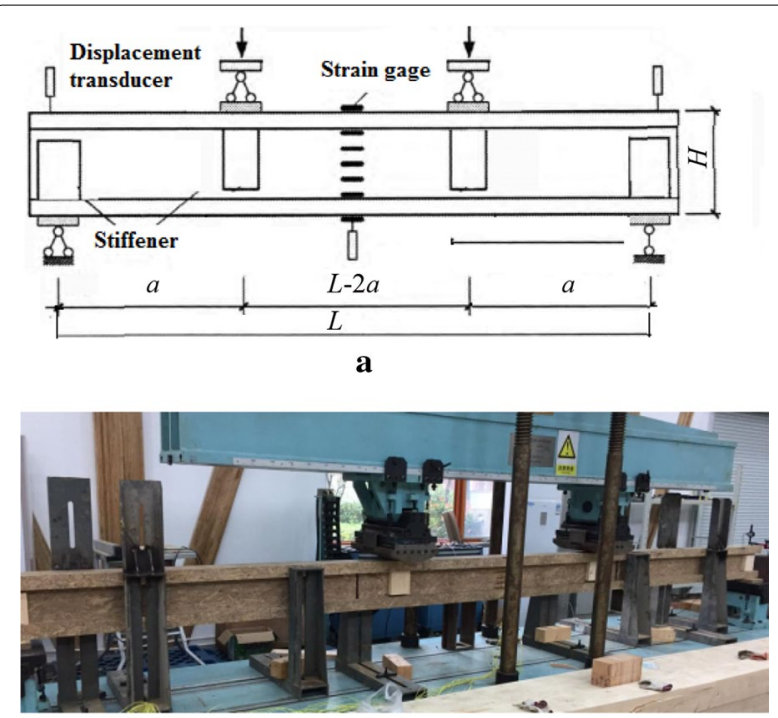

b

Fig. 3 The schematic drawing (a) and photos (b) of the bending test

the web panels in high I-beam resulted in stress concentration at web-to-web joints [15]. It could be concluded that web-to-web joint with nail-glued timber may produce insufficient shear strength for bamboo I-beams with larger depth. Another failure type in B400 was flange failure in buckling (FCB) caused by torsional buckling of specimens. In addition, for bamboo I-beam with a depth of $600 \mathrm{~mm}$ (B600), FCB was also observed (Fig. 4d). For I-beam made of wooden flange (W300), FT of the bottom flange induced by knots (Fig. 4b), or SF at the location of web-to-web joint was observed.

\section{Influencing factors of bending test}

The load and mid-span displacement curves of I-beams bending test are shown in Fig. 5 . In the bending test, the load increased nearly linearly with the displacement until it reached the failure load, which showed a brittle failure. Under a deformation of $L / 250(24 \mathrm{~mm})$ considering the serviceability criterion, the load-displacement curves of all specimens were linear, which was consistent with the experimental phenomenon that the specimen had no obvious damage at this stage.

The results in Table 3 show that its mechanical properties $\left(M_{\mathrm{u}}\right.$ and $\left.(\mathrm{EI})_{0}\right)$ of bamboo I-beam exceeded the requirements of APA EWS Performance-Rated I-joist in PRI-400-2012 [21]. Despite the influence of the flange finger-joint, the average bending stress value (35.71 MPa) obtained in B300-1 was slightly higher than the LBSL tensile strength (34.72 MPa) (Table 1$)$. This was attributed primarily to secondary processing with adhesive and pressing during the subsequent fabrication of the bamboo I-beams. It was also found that the average shear stress value (15.03 MPa) of $\mathrm{B} 600$ was larger than those of I-beam B300-3 and B400, which was related to the span depth ratio of experimental setup.
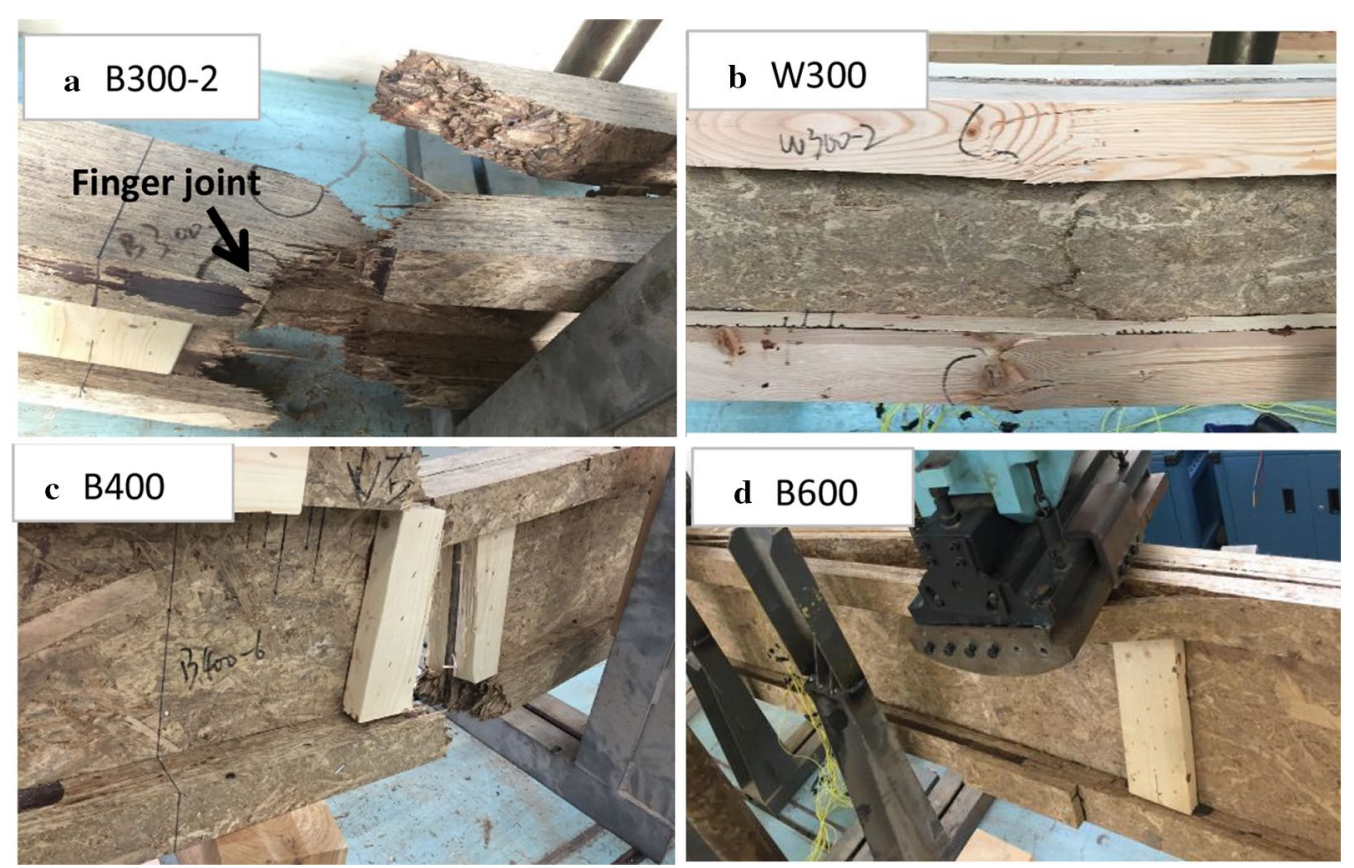

Fig. 4 I-beam failure pattern: a FTJ; b FT caused by knot; c SF in the nail-glued junction; d FCB 


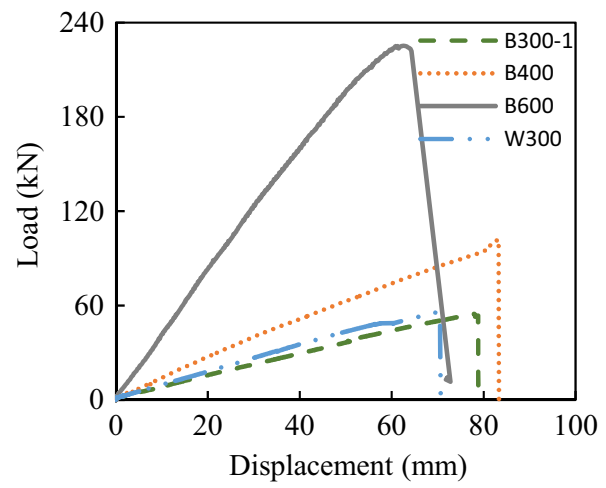

Fig. 5 Load-displacement curves of bending test on the mid-span of different I-beams

Compared with those of B300-1, $M_{\mathrm{u}}$ and mid-span displacement at moment capacity $(w)$ values of B300-2 with reinforcement on flange finger joints increased by about $38.10 \%$ and $62.70 \%$, respectively, as shown in Table 3, indicating that the reinforcement had a remarkable contribution to the improvement of I-beam ultimate load capacity. Racher et al. [15] also proposed reinforcing the finger joints by bonding additional materials, such as carbon fiber or fiber-reinforced polymers, to the surface of the lam. However, there was no obvious difference in stiffness between B300-1 and B300-2. By analyzing the failure mode of B300-2, it can also be concluded that the bending failure of the beam was mainly from the damage at the flange finger joint, which indicated that the flange finger joint was the weak point.

W300 and B300-1 did not show obvious difference in $M_{\mathrm{u}}$ and $\sigma$ (Table 3), which indicates that flange material (timber or LBSL) did not have remarkable impact on the ultimate load capacity of I-beam. Similar results were reported by Wan et al. [22]. They found that the modulus of rupture of I-beam was not significantly affected by the material of the flange (timber or laminated veneer lumber). The factors including joint type in web, flange finger joint and knot of timber could affect the ultimate load capacity. However, W300 showed considerably higher stiffness values $\left(3.39 \times 10^{12} \mathrm{~N} \mathrm{~mm}^{2}\right)$ than B300-1 $\left(2.76 \times 10^{12} \mathrm{~N} \mathrm{~mm}^{2}\right)$, as listed in Table 3. This was related to the high bending modulus of the timber flange, and the flexural properties of I-beams were highly affected by flange stiffness [23]. Due to the fact that bamboo-timber composite I-beam is lighter than the pure bamboo I-beam, bamboo-timber composite I-beam could be more suitable for some applications with strict structural dead weight requirements.

$M_{\mathrm{u}},(\mathrm{EI})_{0}$, and $w$ showed minor difference between B300-2 and B300-3 (Table 3). No failure at web joints also indicated that both types of web joint could provide enough shear strength for the jointed webs of the bamboo I-beams with a depth of $300 \mathrm{~mm}$.

For the bamboo I-beams with the same type of web joint and reinforcement of finger-joint flange, when the beam depth varied from 300 to $600 \mathrm{~mm}, M_{\mathrm{u}}$ value varied from 79.21 to $230.10 \mathrm{kN} \mathrm{m}$, as listed in Table 1. The ultimate load capacity increased as the depth increased. It was also found that in a previous study that the ultimate load capacity increased considerably with the increase in section depth [24]. Moreover, $w$ value gradually decreased along with increasing depth of cross-section. The results revealed that the stiffness can be improved by changing the shape of the cross-section, and the bending deformation of bamboo I-beam obviously reduced. Chui et al. [25] investigated natural fiber composites for reinforcing the flanges of wood I-beams to improve the stiffness. The stiffness can also be improved by bonding additional materials with high modulus as well [26]. Meanwhile, the loads of $P_{L / 250}$ in the serviceability criterion of B300-3, B400 and B600 were 23.35,33.61 and $43.66 \%$ of the ultimate loads, respectively. Therefore, due to the low stiffness and large deformation of bamboo I-beams, deformation control should be considered during design and construction.

\section{Cross-sectional strain distribution at the mid-span of beams}

The load-strain curves of the 7 measurement points on the mid-span cross-section of W300 and B600 are shown

Table 3 Mean values of I-beam mechanical properties

\begin{tabular}{|c|c|c|c|c|c|c|c|}
\hline Beam type & $P_{\max }(\mathrm{kN})$ & $P_{L / 250}(\mathrm{kN})$ & $M_{\mathbf{u}}(\mathrm{kN} \mathrm{m})$ & $w(\mathrm{~mm})$ & $(E I)_{0}\left(\times 10^{12} \mathrm{~N} \mathrm{~mm}^{2}\right)$ & $\sigma(\mathrm{MPa})$ & $\tau(\mathrm{MPa})$ \\
\hline B300-1 & $54.76(9.71 \%)$ & $18.66(7.95 \%)$ & $57.50(9.72 \%)$ & 70.01 (4.02\%) & $2.76(7.57 \%)$ & $35.71(9.71 \%)$ & $7.81(9.71 \%)$ \\
\hline B300-2 & $75.63(8.47 \%)$ & $17.66(10.52 \%)$ & $79.41(8.47 \%)$ & 113.89 (10.22\%) & $2.63(3.56 \%)$ & $49.32(8.47 \%)$ & $10.79(8.47 \%)$ \\
\hline B300-3 & $75.44(7.96 \%)$ & $16.45(9.52 \%)$ & $79.21(7.96 \%)$ & 115.01 (9.33\%) & $2.64(9.56 \%)$ & $49.20(7.96 \%)$ & $10.76(7.96 \%)$ \\
\hline W300 & $57.80(12.87 \%)$ & $21.6(6.40 \%)$ & $60.76(12.85 \%)$ & $69.48(11.22 \%)$ & $3.39(11.55 \%)$ & $36.26(12.80 \%)$ & $7.93(12.82 \%)$ \\
\hline B400 & $97.16(6.68 \%)$ & $32.66(3.07 \%)$ & $102.01(6.62 \%)$ & 82.85 (10.99\%) & $4.93(6.27 \%)$ & $41.00(6.69 \%)$ & 9.99 (6.64\%) \\
\hline $\mathrm{B} 600$ & 219.15 (3.93\%) & $95.69(4.77 \%)$ & $230.1(3.93 \%)$ & 60.89 (3.96\%) & 16.7 (4.59\%) & $40.88(3.93 \%)$ & $15.03(3.93 \%)$ \\
\hline
\end{tabular}

Values in parentheses are coefficient of variation 
in Fig. 6. The strain increased linearly with the increase of load. When the load reached its maximum, all beams were completely destroyed. The absolute values of maximum compression strain were roughly equal to those of maximum tension strain for all of these I-beams.

Under different loading levels, the strain of I-beams from measurement points 1-7 distributed almost linearly, as shown in Fig. 6 . The strains of the middle measurement points (4) were almost equal to zero. Therefore, the neutral axis lay on the centroid of a beam cross-section. As well, the hypothesis theory of bending plane of materials was demonstrated. There was a compressive (negative) strain above the neutral axis, and a tensile (positive) strain below the neutral axis.

\section{Theoretical calculation}

According to the failure mode, the average moment capacity values were calculated according to formulas (5)-(7), as illustrated in Table 4.
The calculated I-beam moment capacity $\left(M_{\text {cal }}\right)$ according to ASTM D5055-16 [18] was determined as follows:

$$
M_{\text {cal }}=K_{\mathrm{L}} F_{\mathrm{a}} A_{\text {net }} y \text {, }
$$

where $K_{\mathrm{L}}$ is length adjustment factor, $A_{\text {net }}$ is the net area of one flange (excluding areas of all web material and rout), $y$ is the distance between flange centroids (with the rout removed), and $F_{\mathrm{a}}$ is design flange axial stress.

When shear failure occurred at the web joint, the I-beam moment capacity shall be calculated as follows:

$$
M_{\mathrm{cal}}=V_{\mathrm{u}} \times a,
$$

where $V_{\mathrm{u}}$ could be obtained from formula (4) $(\tau=9 \mathrm{MPa}$ for Douglas fir shear strength parallel to grain according to ASTM D143-14 [17]).

The evaluation of the design capacity with regard to stability was dependent on critical moment $M_{\text {cal }}$ [27], and the equation of elastic critical moment is given by:

$$
M_{\mathrm{cal}}=\frac{\pi}{L} \sqrt{\mathrm{EI}_{\mathrm{y}} \mathrm{GI}_{\mathrm{t}}}
$$
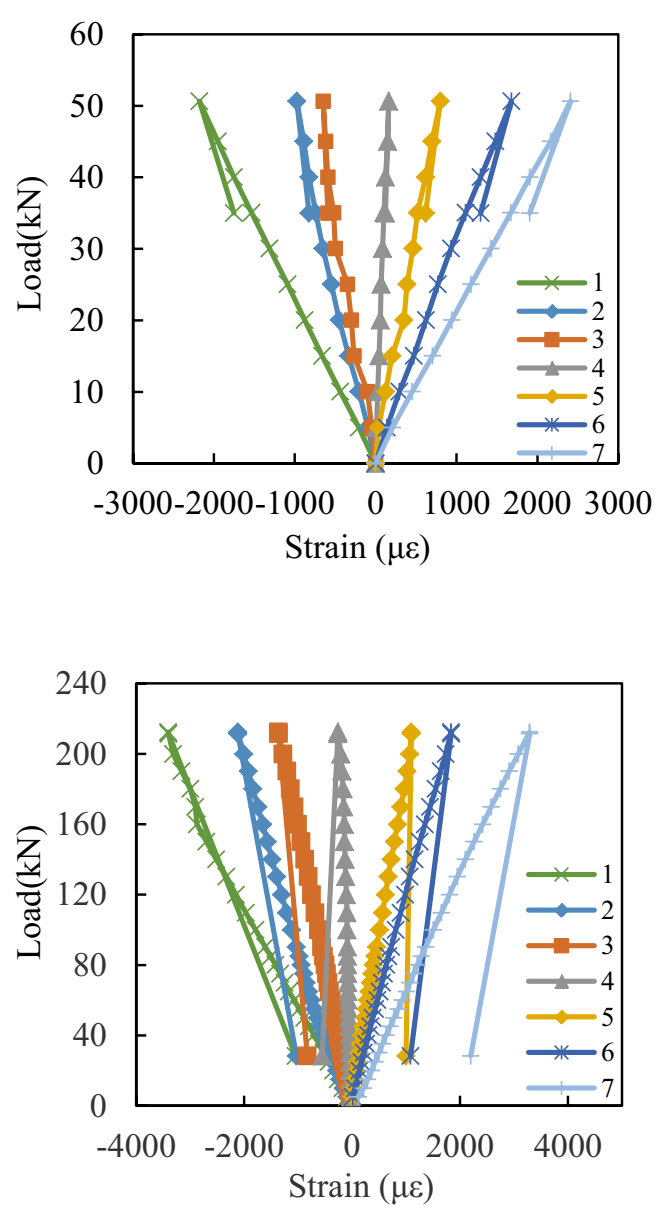
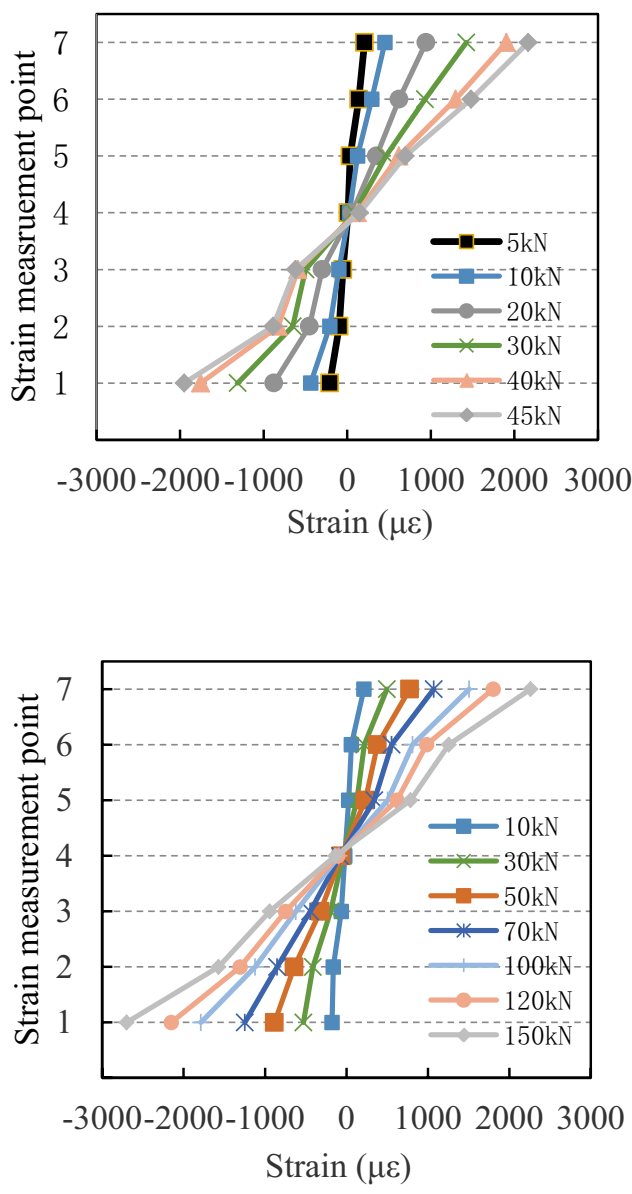

Fig. 6 Typical load-strain curves of the seven measurement points on the mid-span cross-section of W300 (a) and B600 (b) (left column); strain distributions of the 7 measurement points on the mid-span cross-section of W300 (a) and B600 (b) under different loads (right column) 
Table 4 Comparison between calculated values and test results

\begin{tabular}{|c|c|c|c|c|c|c|c|}
\hline Beam type & $M_{\mathrm{u}}(\mathrm{kN} \mathrm{m})$ & $\begin{array}{l}\text { Failure mode } \\
\text { and formula }\end{array}$ & $M_{\text {cal }}(\mathrm{kN} \mathrm{m})$ & $M_{\mathrm{u}} / M_{\mathrm{cal}}$ & $(\mathrm{El})_{0}\left(\times 10^{12} \mathrm{~N} \mathrm{~mm}^{2}\right)$ & $\begin{array}{l}(\mathrm{El}))_{\mathrm{cal}} \\
\left(\times 10^{12} \mathrm{~N} \mathrm{~mm}^{2}\right)\end{array}$ & $(\mathrm{EI})_{0} /(\mathrm{EI})_{\mathrm{cal}}$ \\
\hline B300-1 & 57.50 & FTJ (5) & 64.85 & 0.89 & 2.76 & 3.05 & 0.90 \\
\hline B300-2 & 79.41 & FTJ (5) & 64.85 & 1.22 & 2.63 & 3.05 & 0.86 \\
\hline B300-3 & 79.21 & $\mathrm{FT}(5)$ & 64.85 & 1.22 & 2.64 & 3.05 & 0.87 \\
\hline W300 & 60.76 & $\mathrm{FT}(5) / \mathrm{SF}(6)$ & 159.38/69.92 & $0.38 / 0.87$ & 3.39 & 3.68 & 0.92 \\
\hline B400 & 102.01 & FCB (7)/SF (6) & 95.88/91.95 & $1.06 / 1.10$ & 4.93 & 4.98 & 0.99 \\
\hline B600 & 230.10 & $\mathrm{FCB}(7)$ & 219.34 & 1.05 & 16.70 & 15.82 & 1.06 \\
\hline
\end{tabular}

$$
I_{\mathrm{t}}=\frac{\eta}{3} \sum_{i=1}^{L} d_{i}^{3} b_{i}
$$

where $\mathrm{EI}_{\mathrm{y}}$ is flexural rigidity (minor axis), $\mathrm{GI}_{\mathrm{t}}$ is torsional rigidity, $I_{\mathrm{t}}$ is torsional moment of inertia $d_{i}$ and $b_{i}$ are the height and width of flange and web, respectively, $\eta$ is the connection coefficient of flange and web), $L$ is unbraced length of beam subjected to constant moment in plane of web.

CAS O86-01 [28] specified equations and data for glued composite building components using OSB or glued-laminated timber. The effective stiffness, $(\mathrm{EI})_{\mathrm{cal}}$, of a panel web beam shall be taken as follows:

$$
(\mathrm{EI})_{\mathrm{cal}}=\left(\sum B_{\mathrm{a}}\right) K_{\mathrm{s}} \frac{\left(c_{\mathrm{t}}^{3}+c_{\mathrm{c}}^{3}\right)}{3}+(\mathrm{EI})_{\mathrm{f}} K_{\mathrm{se}},
$$

where $\left(\Sigma B_{\mathrm{a}}\right)$ is sum of axial stiffness of panel webs $\left(\mathrm{N} \mathrm{mm}{ }^{-1}\right), K_{\mathrm{s}}$ is service condition factor for web material, $(\mathrm{EI})_{\mathrm{f}}$ is stiffness of flanges with respect to neutral axis of composite section $\left(\mathrm{N} \mathrm{mm}^{2}\right), K_{\mathrm{SE}}$ is service condition factor for modulus of elasticity of flange, $c_{\mathrm{c}}$ is the distance from neutral axis to compression face $(\mathrm{mm}), c_{\mathrm{t}}$ is the distance from neutral axis to tension face $(\mathrm{mm})$.

Experimental and calculated results are compared in Table 4 , and the ratio of $M_{\mathrm{u}} / M_{\text {cal }}$ is 0.89 in B300-1. The theoretical calculating value was in accordance with experimental value exactly. However, $M_{\mathrm{u}} / M_{\text {cal }}$ of both B300-2 and B300-3 was 1.22. The calculated results were considerably smaller compared with the test values. It was because that reinforcement of flange finger joint caused higher moment capacity. The $M_{\mathrm{u}} / M_{\text {cal }}$ of B400 was 1.06 and 1.10, respectively, according to the formulas (6) and (7). The prediction with high accuracy was obtained according to these formulas. The results carried out for B600 showed good agreement with experiments value. The formula can accurately predict the critical moment of I-beam according to formula (7).

Although the tensile strength of Douglas fir timber was 83.56 MPa (Table 1), because of great influence of knot, the tensile strength of timber with knot became less half the value of timber without knot. Therefore, in the case of
FT caused by knot, the $M_{\text {cal }}$ of W300 calculated according to formula (5) was considerably larger than the experimental value. In the other damage from SF of W300, the $M_{\text {cal }}$ of W300 according to formula (6) was much close to experimental result. Nail-glued timber on web-to-web joint cannot supply sufficient shear strength of jointed web in W300.

In this study, according to the stiffness calculation formula (9), the ratio of $(E I)_{0} /(E I)_{\text {cal }}$ were obtained within the range of $0.86-1.05$ (Table 4$)$. The results indicates that the calculated stiffness was in good agreement with the experimental ones. This formula can correctly theoretically calculate the stiffness of bamboo I-beams and wood I-beam.

\section{Conclusion}

In this study, bamboo I-beams were fabricated with LBSL flanges and BOSB webs. The following main conclusions were obtained by investigating the bending performances:

1. The ultimate load capacity increased as the section depth increased. Moreover, mid-span displacement at moment capacity gradually decreased with increasing depth of section. The stiffness can be improved by changing the size of the cross-section. The failure mode varied with the depth of bamboo I-beam.

2. The ultimate load capacity of I-beam was not obviously affected by the flange material (timber or LBSL). But W300 presented considerably higher stiffness values than B300-1. Due to the fact that bamboo-timber composite I-beam is lighter than the pure bamboo I-beam, bamboo-timber composite I-beam could be more suitable for some applications with strict structural dead weight requirements.

3. The moment capacity and mid-span displacement at ultimate bending moment of B300-2 were improved due to the additional reinforcement on flange finger joints. The reinforcement had sufficient mechanical strength to achieve the desirable improvement 
in ultimate load capacity of B300, however, it had a negative effect on the deformation of I-beam.

4. Based on the stiffness calculation formula of I-beams recommended in Canadian standard and the moment capacity calculation formula corresponding to each failure mode of I-beams, the calculated stiffness and moment capacity of specimens were relatively close to experimental results.

\begin{abstract}
Abbreviations
LBSL: bamboo strand board with bamboo fibers primarily oriented along the length of the member; BOSB: three-layer bamboo orientated strand board with aligned strands on the two surface layers and orthogonally oriented strands in the core layer; FT: flange failure in tension; FTJ: flange failure in tension at finger joint; SF: shear failure; FCB: flange failure in buckling.
\end{abstract}

\section{Acknowledgements}

The authors acknowledge the financial supports of the Foundation of International Centre for Bamboo and Rattan (No. 1632019002) and the National Key Research \& Development Program of China (2016YFD0600905). The constructive comments from the anonymous reviewers are also greatly appreciated.

\section{Authors' contributions}

YS, ZJ, HL, ZS, CF conceived and designed the experiments; YS performed the experiments. YS and CF wrote the paper. All authors read and approved the final manuscript

\section{Funding}

This work was supported by the Foundation of International Centre for Bamboo and Rattan (No. 1632019002) and the National Key Research \& Development Program of China (2016YFD0600905).

\section{Availability of data and materials}

The data sets supporting the results of this article are included within the article and its additional files.

\section{Ethics approval and consent to participate}

Not applicable.

\section{Consent for publication}

We agree to allow our manuscript being published.

\section{Competing interests}

The authors declare that they have no competing interests.

\section{Author details \\ 1 International Centre for Bamboo and Rattan (ICBR), Beijing 100102, China. \\ ${ }^{2}$ NFGA and Beijing Co-built Key Laboratory of Bamboo and Rattan Science \& Technology, National Forestry and Grassland Administration, Beijing 100102 , China. ${ }^{3}$ China National Accreditation Service for Conformity Assessment, Beijing 100837, China.}

Received: 29 April 2019 Accepted: 25 September 2019

Published online: 05 October 2019

\section{References}

1. Plenzler R, Ludwiczak-Niewiadomska L, Latusek D (2005) Behaviour of OSB-webbed I-beams subjected to short-term loading. Fol For Pol Ser B 36:27-37
2. Ren $X R$, Dong $C L$, Zhang HJ (2011) Influence of edgewise shearing modulus of elasticity of web on static-bending deflection of wood I-beam. J Southeast For Univ 31(3):61-64

3. Davids WG, Rancourt DG, Dagher HJ (2011) Bending performance of composite wood l-joist/oriented strand board panel assemblies. For Prod J 61(3):246-256. https://doi.org/10.13073/0015-7473-61.3.246

4. Wu SB, Yu LZ, Li JW, Dong GM (2015) Study on mechanical properties of prefabricated wood I-beam wing edge/web interfaces. For Mach Wood Work Equip 5:28-30 (in Chinese)

5. Pozdeeva A (2015) Stress distribution in mechanically jointed timber I-beam. Dissertation, Saimaa University of Applied Sciences Technology

6. Holstein J, Bohnhoff D (2013) Bending properties of wood I-sections fabricated with screws and polyurethane adhesive and their connection to concrete foundations. J Struct Eng 139(11):2019-2027. https://doi. org/10.1061/ST.1943-541X.0000772

7. Chui YH, Ghulam P, Lai S (2005) Enhancing shear and bearing strength of wood I-joists. Dissertation, University of New Brunswick

8. Rao S, Gong M, Chui YH, Mohammad M (2012) Effect of geometric parameters of finger joint profile on ultimate tensile strength of single finger-joined boards. Wood Fiber Sci 44(3):263-270

9. Dixon PG, Malek S, Semple KE, Zhang PK, Smith GD, Gibson $\sqcup$ (2017) Multiscale modelling of moso bamboo oriented strand board. BioResources 12(2):3166-3181. https://doi.org/10.15376/biores.12.2.3166-3181

10. Semple KE, Zhang PK, Smola M, Smith GD (2015) Hybrid oriented strand boards made from moso bamboo (Phyllostachys pubescens, Mazel) and Aspen (Populus tremuloides, Michx): uniformly mixed single layer unidirectional boards. Eur J Wood Wood Prod 73(4):515-525

11. Wang G, Jiang ZH, Cheng FM, Cheng HT, Sun FB (2014) Manufacture situation and problem analysis on large size bamboo engineering material in China. China For Prod Ind 41 (1):48-52 (in Chinese)

12. Paniagua $V$, Moya R (2014) Flexural performance of I-Joist fabricated with Glue-Laminated bamboo and plywood. Open J Civil Eng 4(3):209-216. https://doi.org/10.4236/ojce.2014.43018

13. Chen G, Zhang QS, Huang DS, Li HT (2015) Bending tests of OSB webbed bamboo I-joists. J Hunan Univ 5:72-79 (in Chinese)

14. Guan YH, Xiao Y (2016) Investigation on bending behavior of glulam I-shaped joint. Ind Constr 46(6):79-82 (in Chinese)

15. Racher P, Bocquet JF, Bouchair A (2007) Effect of web stiffness on the bending behaviour of timber composite I-beams. Mater Design 28(3):844-849. https://doi.org/10.1016/j.matdes.2005.10.019

16. ASTM D1037-12 (2012) Standard test methods for evaluating properties of wood-base fiber and particle panel materials. ASTM International, West Conshohocken

17. ASTM D143-14 (2014) Standard test methods for small clear specimens of timber. ASTM International, West Conshohocken

18. ASTM D5055-16 (2016) Standard specification for establishing and monitoring structural capacities of prefabricated wood I-Joists. ASTM International, West Conshohocken

19. Chen FM, Jiang ZH, Wang G, Li HD, Smith LM, Shi SQ (2016) The bending properties of bamboo bundle laminated veneer lumber (BLVL) double beams. Constr Build Mater 119:145-151. https://doi.org/10.1016/j.conbu ildmat.2016.03.114

20. Mark A, Luisa MG, Enrique HM (2010) Engineered bamboo l-Joists. J Struct Eng 136(12):1619-1624. https://doi.org/10.1061/(ASCE)ST.1943541X.0000235

21. PRI-400 (2012) Performances for APA EWS I-joints used in residential floors. APA-The Engineered Wood Association, Tacoma

22. Wan AR, Wan MN (2000) Bending performance of I-Joists from jointed oriented strand board (OSB) web and laminated veneer lumber (LVL) flanges. Dissertation, University Putra Malaysia

23. Campos MBS, Del Menezzi CHS, de Souza MR (2012) Flexural properties of wood I-beams flanged with tropical hardwoods. JTrop For Sci 24(3):358-367

24. Hindman DP, Bamberg CR, Nussbaum MA (2014) Bracing of wood composite I-Joists to resist lateral buckling from walking loads. J Constr Eng M 140(9):401-403. https://doi.org/10.1061/(ASCE)CO.1943-7862.0000866

25. Chui YH, Komatsu K, Jung K (2008) Reinforcement of wood I-joists with natural fibres. Dissertation, University of New Brunswick

26. Zhong Y, Wu G, Ren H, Jiang Z (2017) Bending properties properties evaluation of newly designed reinforced bamboo scrimber composite 
beams. Constr Build Mater 143:61-70. https://doi.org/10.1016/j.conbu ildmat.2017.03.052

27. Feng Q (2009) The main structural properties of wood I-Joist in application for light frame wooden building. Dissertation, Southwest Forest University (in Chinese)

28. CSA O86-01 (2014) Engineering design in wood. Canadian Standard Association, Mississauga

\section{Publisher's Note}

Springer Nature remains neutral with regard to jurisdictional claims in published maps and institutional affiliations.
Submit your manuscript to a SpringerOpen ${ }^{\odot}$ journal and benefit from:

- Convenient online submission

- Rigorous peer review

- Open access: articles freely available online

- High visibility within the field

- Retaining the copyright to your article

Submit your next manuscript at $\boldsymbol{\nabla}$ springeropen.com 